\title{
MICRO- AND NANOPARTICLES FROM HEMP SHIVES AND HEMP CELLULOSE IN PAPERMAKING
}

\author{
MARIANNA LAKA, ${ }^{*}$ MARITE SKUTE, INESE FILIPOVA, VELTA FRIDRIHSONE,,${ }^{* * *}$ ULDIS \\ GRINFELDS, JURIS ZOLDNERS, ${ }^{*}$ MARTINS SPADE* and IGORS SIVACOVS* \\ *Latvian State Institute of Wood Chemistry, 27, Dzerbenes Str., LV1006 Riga, Latvia \\ **Institute of Polymer Materials, MSAC, Riga Technical University, 3, Paula Valdena Str., \\ Riga LV1048, Latvia \\ $\bowtie$ Corresponding author: Inese Filipova, inese.filipova@inbox.lv
}

Received June 26, 2020

\begin{abstract}
Nano- and microparticles were produced from hemp shives and hemp cellulose obtained thereof, using the thermocatalytic mechanical destruction method. The partially destructed material, at concentrations of $8-9 \%$, was dispersed in water medium in a ball mill or ground without the presence of water in a ball mill $(\sim 15 \mathrm{~h})$. In the first case, a gel-like dispersion, which contained nanoparticles and microparticles, was obtained. In the second case, microparticle powder (from hemp shives) was obtained. The obtained materials were used as fillers and coatings in paper sheets. The air resistance and mechanical properties of paper sheets were investigated. It has been established that the nano/microparticle fillers improve the mechanical properties and air resistance of paper sheets. The properties of paper are improved also by coatings made from nanoparticle gels on both sides of paper sheets. Therefore, the nano/microparticle fillers and coatings obtained from hemp shives and hemp cellulose can be used in papermaking, improving the properties of paper sheets.
\end{abstract}

Keywords: nano- and microparticles, hemp shives, hemp cellulose, air resistance, tensile strength, burst strength

\section{INTRODUCTION}

Recently, there have been a lot of studies in which nanocellulose $e^{1-3}$ is used as filler or for making coatings in polymer and paper materials. Nanocelluloses have been increasingly used in composites since their reduced size, high aspect ratio and stiffness give great strength to the materials. Paper filled with nanoparticle fillers has much higher burst and tensile strength. In many studies, nanocellulose was used for obtaining coatings, which were cast on the surface of paper sheets.

In the study by Zhu et al. ${ }^{4}$ composite paper with coatings made from dissolved cellulose in ionic liquid was investigated. Both the dry and wet tensile strengths were found to be dramatically increased compared to the case of the control paper. The composite paper exhibited dramatically decreased oxygen permeability and enhanced hydrophilicity, as well as strong waterresistant and shape-retaining properties in water. In our earlier works, it has been shown that the fillers and coatings obtained from nanoparticle gels produced from wood processing wastes and fine fibre cellulose considerably improve paper properties. $^{5-9}$

At present, it is of interest to use nanoparticles obtained from hemp in papermaking. Recently, products obtained from hemp have been widely applied. ${ }^{10-12}$ Thus, for example, hemp seeds are used as food source, animal feed, and for obtaining seed oil, which contains essential fatty acids, such as omega 3 and omega 6 . From hemp, a phosphorus-containing product, phytin, can be isolated for its use in medicine. Phytin cures anaemia, and improves bones, nerves and endurance. Hemp oil is also used for technical and industrial applications in paint and plastic manufacture. Stems are used for cordage, woven textiles, building materials, paper, and bedding. All parts, especially female flowers and resins, are used for obtaining recreational drugs (marijuana, hashish). However, at present, hemp shives are not used intensively. Their scarce utilization 
includes the application for obtaining packaging fillers and bedding.

In this work, the use of nano- and microparticles produced from hemp shives and hemp cellulose in papermaking was investigated.

\section{EXPERIMENTAL}

Materials

Bleached softwood kraft pulp (fibre length 2.10 $\mathrm{mm}$, brightness $88.5 \mathrm{ISO} \%$, ash content $0-0.4 \%$, coarseness $0.14-0.17 \mathrm{mg} / \mathrm{m}$ ) was kindly provided by Metsä Fibre, Finland. Paper sheets produced from recycled fibres by the Ligatne Paper Mill (Latvia) were used for coating tests. Hemp shives, containing $46.5 \%$ cellulose, $26.4 \%$ lignin, $19.7 \%$ hemicelluloses and $7 \%$ extractives, were used for producing Kraft pulp (cellulose) and micro- and nanoparticles.

\section{Obtaining of nano- and microparticles}

Hemp shives and the Kraft pulp obtained from hemp shives were used as a source for micro- and nanoparticles. The Kraft pulp from shives was produced by the sulphate method in a $2 \mathrm{~L}$ laboratory autoclave (the cooking solution contained $4.9 \% \mathrm{H}_{2} \mathrm{~S}$ and $4 \% \mathrm{NaOH}$, hydro modulus was $1: 5$, cooking duration $75 \mathrm{~min}$ at $175{ }^{\circ} \mathrm{C}$ ), with a $35 \%$ yield and $4.25 \%$ lignin content.

The nano- and microparticles were obtained using the thermocatalytic mechanical destruction method developed at the Laboratory of Cellulose of the Latvian State Institute of Wood Chemistry. ${ }^{13}$

According to this method, hemp shives and cellulose obtained thereof, reduced to small pieces, were impregnated with a thermocatalytic destruction catalyst, weak hydrochloric acid (0.05-1.0\%). The modulus was 1:20. After pressing out the excessive liquid, the pulp was thermally treated at a temperature of $120{ }^{\circ} \mathrm{C}$ until a dry state was reached. As a result of such a treatment, the destruction of the amorphous part of cellulose occurred, while the crystalline one remained almost intact. The degree of polymerization decreased and reached the so-called levelling-off degree of polymerization (LODP) which, in the case of cellulose, was 250 units.

For obtaining nanoparticles, the partially destructed material (hemp shives or hemp cellulose) was dispersed at a concentration of $\sim 9 \%$ in distilled water in a ball mill. The milling jar was made from aluminafortified porcelain, with a capacity of $5.7 \mathrm{~L}$. Cylindrical grinding media from corundum $2.1 \mathrm{~cm} \mathrm{x}$ $2.1 \mathrm{~cm}$ in size were used; charging factor was $1 \mathrm{kgL}^{-1}$; dispersion time $\sim 15 \mathrm{~h}$. Under the action of high shear stress, the particles were separated and gel-like dispersions or simply gels were formed. ${ }^{14}$

The size of the nanoparticles was obtained by the dynamic light scattering (DLS) method, using a Zetasizer Nano ZS90 (Malvern Instruments Ltd., UK).
It has been established that the majority of nanoparticles had the average length of $\sim 500 \mathrm{~nm}$.

For obtaining microparticles, the partially destructed pulp was ground in a ball mill without the presence of water. Grinding time was $\sim 15 \mathrm{~h}$. As a result, microcrystalline cellulose powder was obtained. The shape and size of the microparticles were investigated using a TESCAN 5136 scanning electron microscope.

\section{Use of the obtained nano- and microparticles in paper sheets}

The obtained nano- and microparticles were used in paper sheets as fillers, as well as coatings on paper sheets.

In the case of fillers, the obtained powders and gels were introduced in the paper furnish in different amounts. The filler content was 5, 10, 15, 20 and 25\% (on dry matter). Paper sheets with and without fillers were prepared according to ISO 5269-2: 2004, with a Rapid Köthen paper machine (PTI, Austria).

In the case of coatings, they were made from nanoparticle gels and applied on both sides of commercially produced paper sheets. Coatings were made using a Control Coater 202 (RK Print Instruments Ltd., UK). Gel concentration was 4, 6, 8 and $10 \%$. In the suspension form, the coating thickness was $24,40,60$ and $100 \mu \mathrm{m}$. Owing to the partial diffusion of the gel into the paper pores and water evaporation, the coating thickness decreased after drying.

Final thickness was determined as the difference (divided by two) in the thicknesses of coated and uncoated paper.

\section{Investigation of the properties of paper sheets}

The air resistance and mechanical properties of paper sheets were investigated. Air resistance was determined according to ISO 5636-3:2013, using an L\&W Air Permeance Tester. Tensile strength was determined on a Frank Tensile Tester (Frank-PTI, Austria) according to ISO 1924-2:2008. Burst strength was determined on a Frank Burst Tester for Paper (Frank PTI, Austria) according to ISO 2758:2014. The StD of mechanical indices was below $\pm 4 \%$.

\section{RESULTS AND DISCUSSION \\ Effect of the microparticle filler on the properties of paper sheets}

Figure 1 shows scanning electron micrographs of microparticles obtained from hemp shives. It can be seen that the microparticle powder contains particles with almost similar dimensions in the longitudinal and transversal directions.

Figure 2 demonstrates the percentage distribution graphs of the number of particles in the longitudinal and transversal directions. The 
majority of powder particles have the size of 5-9 $\mu \mathrm{m}$ in the longitudinal and transversal directions.

Figure 3 shows the tensile and burst indices of paper sheets versus the microparticle filler content. It can be seen that, with increasing filler content up to $10 \%$, the tensile and burst indices increase and then, at greater filler content, decrease again. It can be explained by the fact that, at small amounts of the fillers, they fill the voids between the cellulose fibres and the strength increases.

However, at great amounts of the fillers, the strength is determined by the bonds between the cellulose fibres and the particles of the shives, and it is weaker than that determined by the bonds among the cellulose fibres. At the filler content of
$10 \%$, the tensile index and the burst index increased by $4 \%$ and $8.5 \%$, respectively.

The microparticle filler did not affect the air resistance of paper sheets.

\section{Effect of the nanoparticle filler on the properties of paper sheets}

Figure 4 demonstrates the tensile index and burst index of paper sheets versus the hemp shive and hemp cellulose nanoparticle filler content. Both of these indices increase with increasing filler content. The hemp shive nanoparticle filler increases the mechanical indices more in comparison with the hemp cellulose nanoparticle filler.

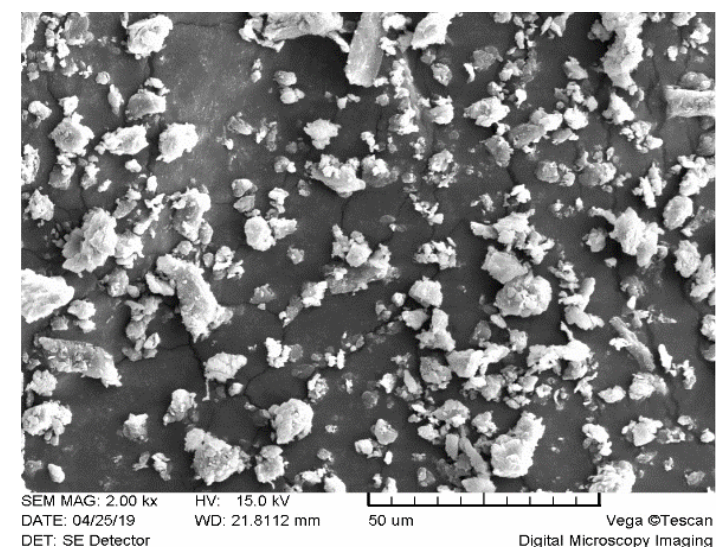

Figure 1: Scanning electron micrographs of microparticles obtained from hemp shives

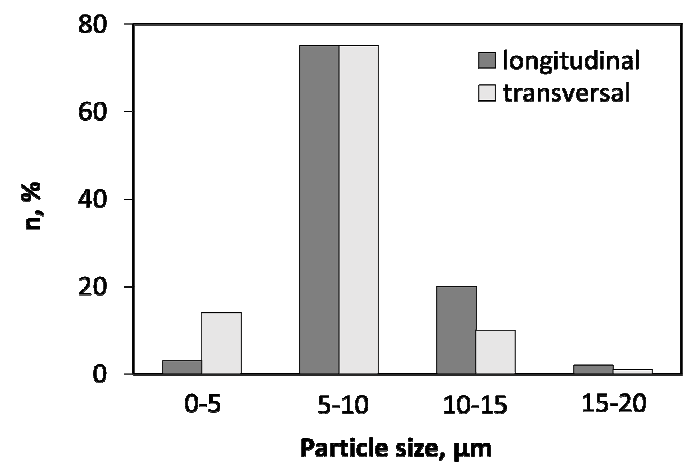

Figure 2: Percentage distribution graphs of the number of microparticles obtained from hemp shives in the longitudinal 1 and transversal d directions

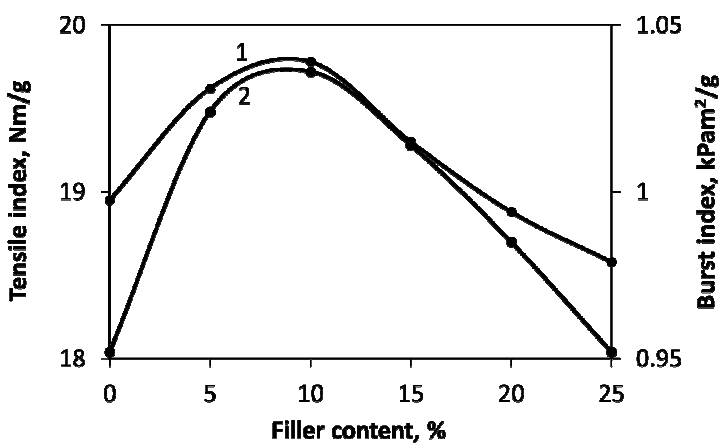

Figure 3: Influence of microparticle filler content on mechanical properties of paper $(1-$ tensile index, 2 burst index) 
MARIANNA LAKA et al.

25
24 
coating thickness of $20 \%$, it increases by $15 \%$, but for hemp cellulose nanoparticle gels - by $47 \%$, respectively. Especially, the coatings made from hemp cellulose nanoparticle gels increase the air resistance of paper sheets. Thus, the air resistance in the case of the coatings made from hemp cellulose $8 \%$ nanoparticle gels, at a coating thickness of $25 \mu \mathrm{m}$, increases 800 times (Fig. 9).
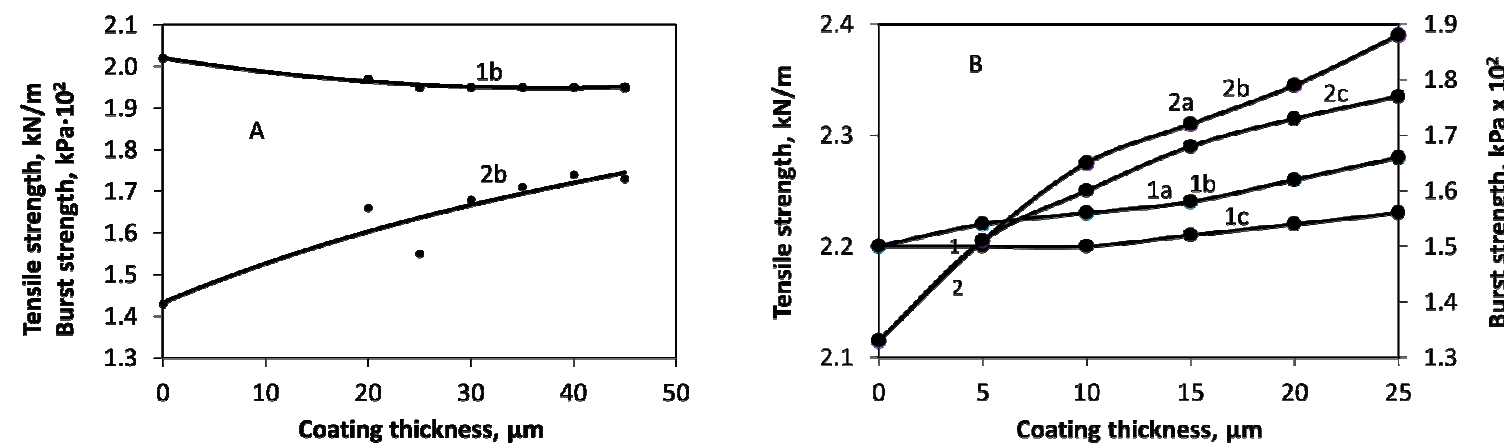

Figure 7: Influence of coating thickness made from hemp shive (A) and hemp cellulose (B) nanoparticle gels with concentrations of $4 \%$ (a), $6 \%$ (b) and $8 \%$ (c) on mechanical properties of paper (1 - tensile strength, 2 - burst strength)
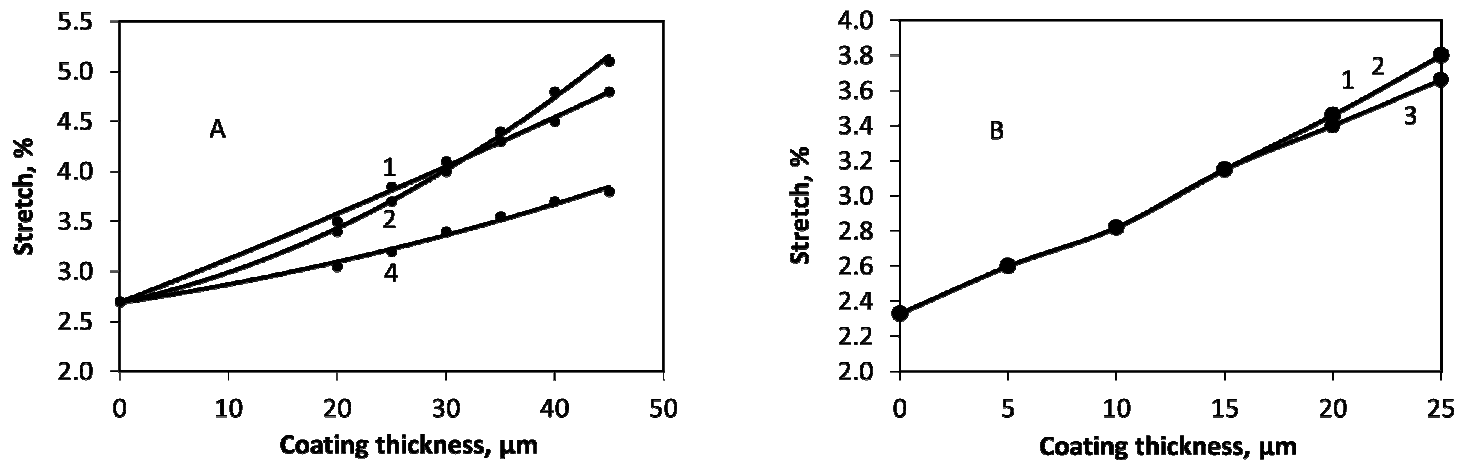

Figure 8: Influence of coating thickness made from hemp shive (A) and hemp cellulose (B) nanoparticle gels with concentrations of $4 \%(1), 6 \%$ (2) and $8 \%$ (3) on stretch of paper

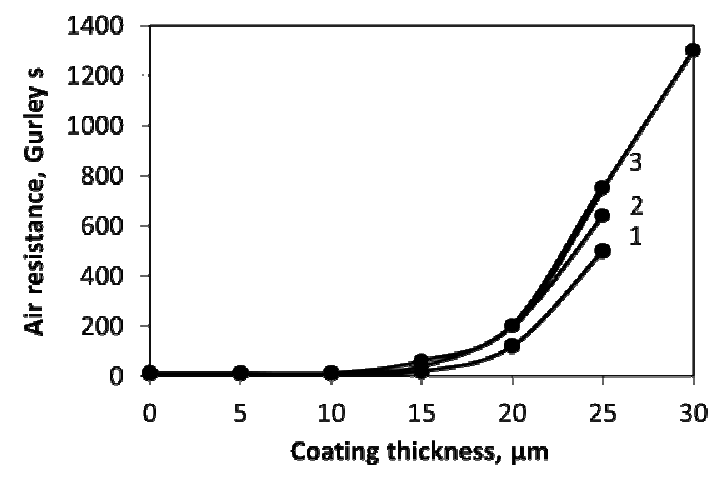

Figure 9: Influence of coating thickness made from hemp cellulose nanoparticle gels with concentrations of 4\% (1), $6 \%$ (2) and $8 \%$ (3) on air resistance of paper

\section{CONCLUSION}

From hemp shives and hemp cellulose, microparticles and nanoparticles were obtained, and were used as fillers in paper sheets and for making coatings (in the case of nanoparticles) on both sides of paper sheets.

It has been established that micro- and nanoparticle fillers improve the mechanical properties of paper sheets. Nanoparticle fillers 
improve the mechanical properties to a greater extent, and also improve the air resistance of paper sheets.

The coatings made from nanoparticle gels also improve the properties of paper sheets. Especially the coatings made from hemp cellulose increase the air resistance of paper sheets.

The micro- and nanoparticle fillers and coatings (in the case of nanoparticles) obtained from hemp shives and hemp cellulose can be used in papermaking for improving the mechanical and barrier properties of paper sheets.

ACKNOWLEDGEMENT: The study is financed by the Latvian State Institute of Wood Chemistry Bioeconomy grant "Complex processing of the hemp and its products".

\section{REFERENCES}

1 A. Dufresne, Curr. Opin. Colloid In., 29, 1 (2017), https//doi.org/10.1016/j.cocis.2017.01.004

2 A. F. Lourenco, J. A. F. Gamelas, P. Sarmento and P. J. T. Ferreire, Carbohyd. Polym., 224, 115200 (2019), https://doi.org/10.1016/j.carbpol.2019.11520

3 M. He, B.-U. Cho and J. M. Won, Carbohyd. Polym., 136, $820 \quad$ (2016), https://doi.org/10.1016/j.carbpol.2015.09.069

4 R. Zhu, X. Liu, P. Song, M. Wang, F. Xu et al., Carbohyd. Polym., 200, $100 \quad$ (2018), https://doi.org/10.1016/j.carbpol.2018.07.069

5 M. Laka, S. Chernyavskaya, A. Treimanis, I. Birska and L. Vikele, in Procs. $4^{\text {th }}$ International Scientific Conference on Hardwood Processing, Florence, Italy, October 7-9, 2013, pp. 354-355

6 M. Laka, L. Vikele, L. Rozenberga and S. Janceva, in Procs. AIP Conf., 2016, pp. 020112-1-020112.-4, https://doi.org/10.1063/1.49498

M. Laka, A. Treimanis, S. Chernyavskaya, M. Skute, L. Rozenberga et al., Holzforschung, 69, 745 (2015), https://doi.org/10.1515/hf-2014-0271
8 M. Laka, M. Skute, S. Janceva, V. Fridrihsone, I. Sable et al., Solid State Phenom., 267, 12 (2017), https://doi.org/10.4028/www.scientific. net/SSP.267.12 9 M. Laka, M. Skute, I. Filipova, V. Fridrihsone, U. Grinfelds et al., Cellulose Chem. Technol., 54, 113 (2020), https://doi.org/10.35812/CelluloseChemTechnol.2020. 54.13

10 W. Stanwix and A. Sparrow, "The Hempcrete Book. Designing and Building with Hemp-lime", UIT Cambridge Ltd., 2014

11 P. Bouloe, S. Allegret and L. Arnaud, "Hemp: Industrial Production and Uses", Wallingford, UK, CABI, 2013

12 R. C. Clarke and M. D. Merlin, "Cannabis. Evolution and Ethnobotany", Berkeley, Los Angeles, London, University of California Press, 2013

13 M. Laka and S. Chernyavskaya, Latvian Republic Patent No. 11184 (1996)

14 M. Laka, S. Chernyavskaya, L. Faitelson and E. Jakobsons, Applied Mechanics and Engineering, 4, (Special Issue: "ICER '99”), 351 (1999) 